\title{
Conference: The Amphibians and Reptiles of Scotland: current research and future challenges
}

\author{
J.R. Downie \\ University of Glasgow, Glasgow Natural History Society (GNHS), Froglife, and Clyde Amphibian and Reptile \\ Group (CARG) \\ School of Life Sciences, Graham Kerr Building, University of Glasgow, Glasgow G12 8QQ \\ E-mail: roger.downie@glasgow.ac.uk
}

\section{OPENING REMARKS}

Welcome to the conference, organised as a contribution to Glasgow Science Festival, 2018. I am delighted that the conference is supported by so many organisations: Glasgow Natural History Society, Scottish Natural Heritage (SNH), Froglife, Amphibian and Reptile Groups-UK, Amphibian and Reptile Conservation, British Herpetological Society, and Friends of Angus Herpetofauna. Their support allowed attendance at this conference to be free of charge. Please visit their stalls during the breaks.

To my knowledge, this is the third such conference, following Glasgow in November, 2011 and Edinburgh in October, 2014. Previous meetings in Scotland were part of the series of Herpetofauna Workers meetings which occur annually at different venues around the country.

The immediate stimulus for us in organising this conference was the publication, in 2016, of Chris McInerny and Pete Minting's The Amphibians and Reptiles of Scotland (McInerny \& Minting, 2016). As far as I know, this was the first attempt to put together a comprehensive account of Scotland's herpetofauna. GNHS acted as the book's publisher, and some of us felt that it could act as a stimulus for further work, since, as well as collating a large amount of information, the book drew attention to gaps in our knowledge; hence the subtitle of the meeting: current research and future challenges. One obvious gap is the lack of recording in some parts of Scotland, contributing to some big blanks on the distribution maps.

To make the conference of enduring value, the Proceedings will be published in The Glasgow Naturalist, Scotland's leading natural history journal, now freely available on-line. In addition to the exciting range of talks on the programme, we have a fine set of posters for you to browse during the breaks.

The Scottish Government has designated 2018 as Year of Young People with activities under six themes: participation, education, health and wellbeing, equality and discrimination, enterprise and regeneration, and culture. As our contribution, several of the talks are being given by younger researchers, and the poster display includes work done by young people as part of Froglife's Glasgow Green Pathways project which engages with vulnerable and disadvantaged young people. In addition, as a follow-up to the conference, we have a stall at Science Sunday, Glasgow Science Festival's family day which engages parents and children in the exciting science being done in the city.

In an effort to enlist the support of our politicians, Scottish Environment Link has developed a Species Champion scheme, whereby Members of the Scottish Parliament (MSPs) are encouraged to sign up to champion a particular species, possibly one of particular importance to their constituency. By April 2018, 103 species had champions. Interestingly, reptiles and amphibians are popular with our MSPs with three reptiles [common lizard (Zootoca vivipara), leatherback turtle (Dermochelys coriacea) and slow-worm (Anguis fragilis)] and four amphibians [common toad (Bufo bufo), great crested newt (Triturus cristatus), natterjack toad (Bufo/Epidalea calamita) and smooth newt (Lissotriton vulgaris)] championed. Although no MSP was able to attend the conference, we have received messages of support from Jackie Baillie (Dumbarton), Emma Harper (Dumfries) and Bruce Crawford (Stirling).

Jackie Baillie wrote: "I am happy to support Scottish Environment Link's Species Champion programme, working in partnership with Amphibian and Reptile Conservation to promote the smooth newt. In Scotland, smooth newt populations are in the southern half of the country, where natural pond chemistry is more suitable and industrial development often results in the destruction of amphibian habitat. This makes my constituency, on the banks of Loch Lomond and subject to the National Park's rules on planning and development, the perfect home for the smooth newt. Nevertheless 
the species still faces a number of challenges, including destruction of breeding ponds, introduction of non-native species and pollution. I welcome all speakers and attendees to the Scottish Herpetological Conference and I look forward to future discussions on a national strategy for amphibians and reptiles".

Emma Harper wrote: "I fully support the work of the Glasgow Natural History Society to draw attention to Scotland's fauna, and the plight of many of our species and the threats they face. As species champion for the natterjack toad, I have been following progress for increasing numbers and protecting their habitat on the Solway Coast, which is the area I represent as a South Scotland MSP. I commend the work that the RSPB are doing to preserve and protect the habitats of the natterjack toad. I look forward to supporting RSPB, and I hope to attend future events and work with RSPB and other organisations on this very important matter."

Jackie Baillie's reference to a "national strategy for amphibians and reptiles" highlights another of the stimuli for this conference. Two to three years ago, several members of the Scottish herpetological community discussed ideas for a national strategy with SNH's David O'Brien. We are delighted that a discussion session on SNH's draft strategy forms a key part of the conference, allowing attendees to provide feedback on the strategy's main features.

Finally in these opening remarks, I wish to thank all members of our organising team; in addition to myself, Chris McInerny, Debbie McNeill, Erik Paterson and Louise Smith.

\section{REFERENCE}

McInerny, C.J. \& Minting, P. (2016). The Amphibians and Reptiles of Scotland. The Glasgow Natural History Society, Glasgow. Free download at: www.glasgownaturalhistory.org.uk/books.html 